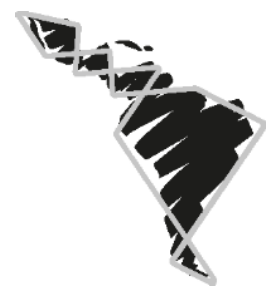

\title{
La autoridad parental de tránsito hacia la humanización de los derechos de la niñez y la adolescencia, cambio de paradigma
}

\author{
Transit Parental Authority Towards \\ the Humanization of the Rights \\ of Children and Adolescents; a \\ Paradigm Change
}

\section{Da autoridade parental à humanização dos direitos da infância e da adolescência: a mudança de paradigma}

María José Aráuz Henríquez ${ }^{1}$

\section{Resumen}

La patria potestad como institución familiar ha sufrido grandes transformaciones que han dado origen a que se estudie el alcance de esta en las relaciones familiares, considerando en el presente estudio el alcance de esta institución desde los derechos y las funciones derivados de la ley para ambos progenitores, con elfin de observar el cambio propuesto por los derechos humanos de los niños y niñas, así como las funciones que derivan, pasando de una autoridad parental en sentido vertical a funciones de guía, apoyo, acompañamiento y representación en cuido y crianza directa de los padres en relación con sus hijos/as. El reconocimiento de los derechos humanos debe hacerse en el ejercicio diario del cuido directo de los hijos e hijas, permitiendo la participación activa que tienen estos en la familia como sujetos de derecho, tal como lo establecen los instrumentos internacionales y la doctrina integral de protección. Debemos cambiar la forma de pensar y avanzar en el pensamiento aplicado en el desarrollo de

1 Docente Universitaria, Jueza de Distrito de Familia, Managua, Jueza de enlace por Nicaragua ante la $\mathrm{HCCH}$, perteneciente a los Jueces de La Haya sustracción Internacional de Niños. Punto de Contacto de IberRed en materia de Derecho de Familia. 
las competencias de estos en sus diferentes etapas. Los tratados internacionales y la normativa interna establecidos en el Código de Familia y en el Código de la Niñez y Adolescencia reconocen los derechos personalísimos de los niños, niñas y adolescentes (en adelante NNA), dando origen a jurisdicciones especializadas en materia de familia, con el fin de atender los derechos de la niñez y adolescencia y garantizar los derechos personalísimos. Desde la familia y las instituciones públicas relacionadas, se recomienda elaborar protocolos o guías de buenas prácticas que ayuden a establecer criterios de interpretación de acuerdo con el principio de interés superior y autonomía progresiva en la toma de decisiones.

Palabras clave: Autoridad parental, interés superior del niño, capacidad progresiva, dignidad de la persona, derechos humanos de la niñez.

\begin{abstract}
Parental authority has undergone major transformations that have led to the study of the scope of family parental relations, considering in this study the scope of this institution from the rights and functions derived from the law for both parents, to observe the changes proposed by the Human Rights of children as well as the functions that derive, moving from a vertical understanding parental authority to guidance, support, accompaniment and representation in the care and direct upbringing of children. The recognition of human rights must be made in the daily exercise of the direct care of the sons and daughters, allowing the active participation that they have in the family as subjects of right, as established in the international instruments and the integral doctrine of protection. The international treaties and the internal regulations established in the Family Code and the Code of Children and Adolescents, recognize the very personal rights of children and adolescents, giving rise to specialized jurisdictions in the family in order to address their rights and to guarantee the most personal rights. It is recommended to elaborate protocols or guides of good practices that help to establish criteria of interpretation according to the principle of superior interest and progressive autonomy in the decision making.
\end{abstract}

Keywords: Parental authority, best interest of the child, progressive capacity, dignity of the person, human rights of childhood.

\title{
Resumo
}

O pátrio poder como instituição familiar sofreu grandes mudanças que levaram ao estudo do seu alcance nas relações familiares. Neste estudo considera-se o alcance desta instituição a partir dos direitos e funções derivadas da lei para ambos os pais, a fim de observar a mudança proposta pelos Direitos Humanos das crianças, bem como as funções que derivam; a mudança consiste empassar de uma autoridade parental, vista desde um sentido verticalà funções de guia, apoio, acompanhamento e representação no cuidado e na educação direta dos filhos. Oreconhecimento dos direitos humanos deve ser feito no exercício cotidiano do cuidado direto dos filhos, permitindo sua participação ativa dentro da família como sujeitos de direito, conforme estabelecido nos órgãos internacionais e a doutrina de proteção integral. Devemos modificar o modo de pensar e avançar na mudança de pensamento aplicado no desenvolvimento das competências das crianças nas suas diferentes etapas etárias. Os tratados internacionais eregulamentosinternos estabelecidos no Código da Família e no Estatuto da Criança e do Adolescente reconhecem 
os direitos pessoais das crianças e adolescentes, dando origem a jurisdições especializadas em assuntos de família, a fim de abordar os direitos das crianças e adolescentes, garantir os direitos pessoais, da família e das instituições públicas relacionadas, recomenda-se desenvolver protocolos ou guias de boas práticas que ajudem a estabelecer critérios de interpretação, de acordo como princípio de maior interesse e autonomia progressiva na tomada de decisões.

Palavras chave: Autoridade parental, interesses exclusivos da criança, capacidade progressiva, dignidade da pessoa, direitos humanos das crianças.

\section{Introducción}

La patria potestad como institución familiar ha sido objeto de transformaciones en las últimas tres décadas en Nicaragua; ha venido avanzando desde el derecho civil hasta la creación de normas especializadas de familia, misma que obedece a cambios jurídicos y socioculturales. Cambios que inducen a cuestionamientos de fondo, tanto de la terminología que comporta, así como en las atribuciones y funciones derivadas de la titularidad y ejercicio de este derecho por los miembros que componen la familia.

El propósito del trabajo consiste en establecer un recorrido histórico y normativo de la transición de la patria potestad, analizando el alcance de la autoridad parental y observando en las codificaciones más recientes la tendencia democratizante de este derecho en el ejercicio diario de la familia. Tal ejercicio invita a desarrollar, desde este recorrido, el reconocimiento de las atribuciones derivadas de la patria potestad, autoridad parental o responsabilidad parental, en cuanto a su titularidad y ejercicio, clasificación de la cual carecía anteriormente la estructura normativa, pero que derivada de la práctica se ha desarrollado la clara identificación de los derechos-deberes que involucra su ejercicio. Es decir, la humanización de los derechos del niño y la niña es el punto de partida para los cambios de la nomenclatura y contenido de la autoridad parental.

En equilibrio al acompañamiento que puedan hacer los progenitores en cuanto a la representación y toma de decisiones en relación con sus hijos e hijas, debemos darle un lugar digno en el presente estudio a los derechos personalísimos que son reconocidos a la niñez y adolescencia desde la Convención sobre los Derechos del Niño (1989) (en adelante CDN), de tal manera que el enfoque del presente trabajo se asentará básicamente en la etapa transitoria de este derecho, observando los avances al respecto, la identificación de las atribuciones y funciones que se derivan de la filiación para con los ascendientes en cuanto a los hijos e hijas menores de edad y la identificación de los derechos humanos reconocidos a la niñez y adolescencia en el ejercicio de la autoridad parental. 
Igualmente se hace necesario para garantizar que ese reconocimiento sea eficaz en los diferentes planos de la familia, sociedad y el Estado tal como lo señala el artículo 19 de la Convención Americana sobre Derechos Humanos (1969), conocida como Pacto de San José, someramente mide si en los criterios judiciales en las acciones de cuido y crianza se develan criterios y valoraciones de las autoridades judiciales en cuanto a los derechos de la niñez y adolescencia, en el plano de igualdad en el ejercicio de sus derechos e identificación de la evolución de sus facultades como persona en desarrollo.

Identificar las transformaciones del derecho de familia en la institución de la patria potestad de cara a la humanización de los derechos de la niñez y adolescencia, en la familia, sociedad y Estado, es el objetivo general del presente estudio. Como objetivos específicos se abordan: a) revelar la evolución de la patria potestad-autoridad parental, como institución familiar para entender los cambios de paradigmas en la titularidad y ejercicio parental, b) describir el papel de la niñez y adolescencia en la familia y el reconocimiento de los derechos personalísimos, como miembro activo en el desarrollo de los mismos, identificando los derechos humanos de estos en el acompañamiento familiar a los que están llamados los progenitores, c) especificar los principios de interés superior del niño y autonomía progresiva para garantizar la efectiva tutela en la participación de la niñez y adolescencia en las acciones de cuido y crianza.

El problema radica en la ausencia de fundamentos técnico-jurídicos, en el derecho nicaragüense, que conecte la participación activa de la niñez y adolescencia en asuntos de cuido y crianza, con el respeto a sus derechos humanos, lo que provoca vulneración en la tutela efectiva de sus derechos, tanto en la práctica judicial como por los propios miembros de la familia. Desde la perspectiva del derecho de familia es importante reconocer los derechos personalísimos de cada miembro. Esto da pase a que la familia le reconozca los derechos en forma individual a cada uno de sus miembros y que se comience a estudiar de una forma dinámica y flexible las relaciones generadas entre progenitores, hijos e hijas en el ejercicio diario de la autoridad parental.

El tema ha transitado en la medida en que los Estados han asumido compromisos en relación con los derechos de la mujer, la niñez y adolescencia, lo que ha dado origen a la toma de decisiones en la política pública, creación de instituciones y promoción de reformas de normativas existentes o creación de nuevas que se ajusten a lo indicado y que garanticen a la niñez y adolescencia el respeto a sus derechos personalísimos desde la aplicación de los principios de interés superior del menor y del reconocimiento de la autoridad progresiva. 
En Nicaragua, se ubican estudios anteriores que de forma directa o tangencial desarrollan el tema de la autoridad parental; así, Meza (2004), Orozco (2010) y Abboud (2016), pero el presente estudio es primigenio en cuanto al enfoque de vincularse con el desarrollo de los derechos humanos de la niñez y adolescencia. Sus estudios nos sirven de soporte para el análisis actualizado de la institución a estudiar, en los cuales se han abordado diferentes criterios de aplicación de corte civilista, como de la etapa transitoria que ha recorrido el país en la temática del derecho familiar, así como la observación de la aplicación moderna del contenido del Código de Familia, primero en su historia.

El abordaje que resalta este artículo es desde la niñez y adolescencia y no desde la interpretación de los derechos del adulto, así como el reconocimiento de sus derechos personalísimos en esta nueva perspectiva y del poco conocimiento en la práctica jurídica por parte de los operadores de justicia. En consecuencia, este trabajo constituye uno de los primeros artículos escritos sobre el tema de los derechos personalísimos de la persona en desarrollo en cuanto a la dignidad, libertad e igualdad de trato en la búsqueda de la armonización con los derechos que ejercen los progenitores en relación con su acompañamiento, observando el cambio de paradigma por el cual transita.

El actual trabajo reflexiona la utilidad que tendría para Nicaragua que se elaboren protocolos de actuación para unificar criterios de interpretación, con respecto a este punto se ofrecen luego recomendaciones.

El tema implica el respeto a la dignidad y el reconocimiento de la capacidad progresiva de las personas menores de edad, exige un cambio de conducta de los progenitores, la sociedad y el Estado. Este debe desconstruir los conceptos patriarcales de ver a los hijos e hijas como muebles u objetos, reconociéndoles la dignidad humana, en cuanto al respeto de sus derechos como tales, así como a los derechos personalísimos y las singularidades propias de cada uno de ellos y la progresión de los progenitores en el ejercicio diario del cuido y crianza. Debe cambiar la forma de educar, representar y atender, por un accionar que ayude al crecer y a desarrollar competencias para la vida acompañando, guiando y apoyando.

La presente investigación es de corte descriptivo y documental de tipo cualitativa, el método utilizado es de análisis de contenido abordado de forma deductiva partiendo de lo general que es la institución de la patria potestad, a lo particular en cuanto al control del respeto de los derechos humanos de la niñez y adolescencia en una de las funciones que se deriva de la autoridad parental, acotada a la acción de cuido y crianza. 
Las técnicas aplicadas fueron revisión bibliográfica, nacional e internacional y análisis de sentencias de cuido y crianza de tres juzgados de distrito de familia del año 2016. Las fuentes consultadas fueron leyes y codificaciones de familia de Centroamérica y de Argentina, artículos de revistas científicas relativos a la humanización de los derechos humanos en la familia, y a los principios rectores del derecho de familia relacionados con el interés superior y la autonomía progresiva del niño, niña y adolescente, análisis de datos estadísticos de sentencias judiciales de primera instancia en el Departamento de Managua a un año de vigencia del Código de Familia (en adelante CF), así como el estudio del desarrollo de los casos seleccionados para la observancia de la efectiva aplicabilidad de los derechos de la niñez y adolescencia.

\section{De la patria potestad a la autoridad parental}

\subsection{De la patria potestad a la autoridad parental: superación terminológica que expresa concepciones de fondo}

Las legislaciones civiles derivadas de los códigos napoleónicos regulaban la institución de la patria potestad en la que se otorgaba poder absoluto al padre para disponer y representar al hijo e hija y solo en su defecto la madre podía suplir tales tareas. La patria potestad, como institución del derecho de familia, ha venido evolucionando en los últimos treinta años, como producto de la demanda social y familiar en la necesidad del reconocimiento de los derechos de todos los miembros de la familia. Recordemos que históricamente el padre disponía de todo en la familia, la mujer y los hijos no tenían ningún tipo de participación en las decisiones de esta.

La distinción en las funciones relativas al padre y la anulación de la participación de la madre y los hijos e hijas en la familia no eran observadas en la práctica social, ya que era un hecho permitido que encajaba dentro del contexto histórico derivado de los roles sociales e históricos que le asignaban al hombre como jefe del hogar y a la mujer como la cuidadora de sus hijos e hijas. Vivas (2010) expresa en una idea la forma en que se desarrollaban las funciones y representaciones en la familia, "La jefatura del marido respecto de la mujer, en relación a su persona y a sus bienes se traducía, asimismo, en la jefatura de él para en cuanto a los hijos, lo que encontraba inmediato reflejo en la patria potestad..." (p. 1214).

El ejercicio de la patria potestad ha tenido alcances que la normativa no recoge con claridad, según Velazco (2008), los distingue "en dos aspectos esenciales: el personal y el patrimonial. La esfera personal comprende los deberes y facultades de los progenitores en relación al cuidado y protección de la persona del hijo, mientras 
que en lo patrimonial se encuentran los actos de administración y disposición de sus bienes" (p. 20).

Desde mi punto de vista, los estudiosos deben incluir siempre la representación legal de las personas menores de edad, aunque el hecho de que no la expresen en su texto, no implica que los progenitores no la ejerzan. Pero más allá de lo patrimonial el progenitor o la progenitora deberán ejercer la representación de sus hijos e hijas en el derecho de accionar en nombre de estos para hacer valer derechos que se derivan de la filiación, de tal manera que la representación que se ejerce es inherente a la atribución que la ley les confiere, tanto natural como jurídicamente.

Esta clasificación en la estructura normativa del siglo pasado no se observaba en las legislaciones anteriores, tal como la encontramos en los artículos 244 y 245 del Código Civil (CC) de Nicaragua de 1904. No es hasta en el Decreto 1065 Ley de regulación de las relaciones madre, padre e hijos, publicada en Gaceta Diario Oficial No. 185 del 3 de julio de 1982, que se incluye la participación de la mujer en las obligaciones y los derechos derivados de la maternidad y paternidad, y marca un hito histórico en el cambio de nomenclatura, estableciendo con claridad las atribuciones delegadas por la ley a ambos progenitores.

Consecuentemente, se les deja de llamar patria potestad a estas funciones y atribuciones, y se les denomina relaciones madre, padre e hijos, plasmadas en el referido decreto, utilizando un término más democrático e incluyente de todos los miembros de la familia. En el artículo 1 de la citada ley, se establecían las funciones de cuidado personal, la representación de los hijos e hijas y la administración de los bienes, derogando algunas normas relativas a la patria potestad establecida en el CC.

En la Constitución Política de 1987, se instituye en un solo capítulo el derecho de familia de los artículos 70 al 79 recogiendo en ella en plano de igualdad el derecho del hombre y la mujer a formar una familia, bien sea mediante el matrimonio o la unión de hecho estable. Reconoce el principio de solidaridad y corresponsabilidad en el derecho-deber que tienen ambos progenitores para con sus hijos e hijas, reconoce la igualdad entre ellos, dejando atrás la discriminación de la cual eran objetos cuando eran nacidos fuera del matrimonio. Establece el compromiso claro y preciso de respetar el derecho del niño o niña desde el momento de la concepción y el derecho que tiene la niñez a la identidad, mediante la investigación de la verdad biológica, de igual manera reconoce el derecho a la protección de los adultos mayores.

Así lo describió Gómez (2010), en el contexto histórico, cuando expresa:

El propósito fundamental de esta política es garantizar el cumplimiento del ejercicio pleno del derecho de padres y madres a criar, educar y garantizar el bienestar 
integral de sus hijos e hijas mediante cambios socio culturales, y mecanismos que contribuyan a superar los obstáculos para el goce y disfrute de derechos y responsabilidades (p. 267).

Al respecto, López (2014) nos expresa que para poder superar los obstáculos y garantizar la vigencia de los derechos de los niños es de vital importancia la coordinación interinstitucional entre el Estado y la sociedad.

En las nuevas legislaciones retoman con claridad la distinción de la titularidad y las funciones atribuidas por la ley a ambos progenitores, de ello Abboud (2016) nos menciona que la distinción referida ya existía en la estructura de las codificaciones en leyes de dos países suramericanos y España, en las que se observa con claridad esta partitura, veamos:

Del conceptounitario responsabilidad parental se pueden diferenciar tres elementos: titularidad, ejercicio y cuidado personal. Tal distinción no es asunto nuevo. En códigos civiles como el de Argentina (artículo 264); Chile (artículos 229 y 244) y España (artículos 156, 160), se encontraba ladivisión (p. 43).

De lo anterior Abboud (2016) expresa que aunque las leyes citadas han sido modificadas o reformadas mantienen la estructura de la normativa original, pero los fines son distintos:

... pero tal distinción se ha mantenido y se incorpora en las nuevas leyes. Así, en el vigente $\mathrm{CC}$ y $\mathrm{C}$ se encuentra delimitada la responsabilidad parental en título, ejercicio y cuidado personal de los hijos (artículos 640, 641 y 648); en Chile, la Ley No. 20680/2013 diferencia cuidado personal y patria potestad (artículos 225 y 245) y enEspaña, en la Ley No. 15/2005 se apreciala diferenciaciónterminológica entre cuidado de los hijos e hijas, patria potestad, ejercicio de esta, régimen de comunicación y estancias (artículos 90 a) y 92.4) (p.43).

La transformación de esta institución en el recorrido social e histórico ha dado lugar a que los especialistas estudien el tema. Desde mi punto de vista, la autora aborda con claridad las nuevas codificaciones, las atribuciones y facultades derivadas de la ley para la figura de la institución parental, estableciéndose en el contenido de las normas referidas la clasificación de titularidad, ejercicio y cuidado personal de los hijos e hijas.

Los códigos de familia de la región centroamericana mantienen una clasificación que implícitamente asumen las tres grandes funciones de la autoridad parental, contenidas en los artículos 206, 207, 211 y 223 del Código de Familia de El 
Salvador, artículo 316 de Panamá, artículos 185, 186, 187 de Honduras, artículos 127 y 143 del Código de Familia de Costa Rica y en los artículos 267, 272, 274, 276 y 280 del Código de Familia de Nicaragua.

El estudio de los cuerpos normativos mencionados, y con base en la práctica judicial que tiene la suscrita autora, permiten aportar que la autoridad parental se encuentra estructurada en tres grandes funciones que para efectos de este estudio resultan de fácil comprensión y que grosso modo relacionaré los siguientes alcances:

1. La titularidad, que no es más que la potestad derivada de la norma; es decir, por imperio de ley y por la propia naturaleza los progenitores son los garantes naturales de los hijos e hijas. Es un derecho-deber del cual los ascendentes no disponen, consecuentemente, este derecho no es susceptible de transar, negociar ni de renunciar.Abboud (2016) expresa que “... el cuidado personal de los hijos y las hijas es irrenunciable, en tanto no es un derecho subjetivo, sino una atribución legal. Por otra parte, esa misma atribución legal puede ser delegable en alguno de los progenitores, o a terceras personas afectivamente vinculadas en vía de excepción que confirma la regla de indelegabilidad" (p. 102). Es decir, que los derechos se renuncian y los deberes son susceptibles de delegarse, considero entonces que la autoridad parental establece la titularidad atribuida por ley, esta no puede renunciarse, pero debido a la flexibilidad y la mezcla de las relaciones familiares que dinamizan la realidad, existe la delegación para efectos de una de las acciones de la autoridad parental, es decir, en relación con el cuidado personal, cuando estamos frente a variantes de separación, trabajo o estudio. sin embargo, soy del criterio que entre progenitores no existe delegación de obligaciones, ya que ambos se encuentran obligados a garantizar el desarrollo integral de sus hijos, la delegación cabría cuando los progenitores necesitan de terceras personas, parientes o no, para el cuido directo del hijo o hija.

Jaime (2016) hace la aplicación de la figura de garante en el derecho alimentario, derecho que obliga a ambos progenitores a garantizar el desarrollo integral de los NNA, tal como lo señala el artículo 73 de la Constitución Política de Nicaragua, sin embargo, desde mi punto de vista, la figura del garante de los hijos e hijas se deriva del hecho natural mismo de la paternidad y maternidad responsables hasta que alcancen estos la mayoría de edad. Es decir, que es inherente a la titularidad. Hay que estar claros que los términos de maternidad y paternidad responsables implican una tarea diaria y comprometida en el desarrollo de los hijos e hijas, de forma más acentuada en las etapas de su infancia donde recobran mayor 
importancia la representación parental y el cuido directo de estos, pasando en la etapa de preadolescentes y adolescentes al brindar una asistencia.

2. El ejercicio, que se lleva a efecto mediante el cuido cotidiano que conlleva la construcción de la crianza de la persona en desarrollo, en esta tarea, hay que estar claros que la persona que ejerce este derecho puede ser distinta de los progenitores, aunque ellos aún continúen juntos o separados, así encontramos que por efectos de estudio, trabajo, o bien, de apegos desarrollados entre los hijos e hijas con otros parientes, esta acción se torna dinámica, y muchas veces es ejercida por abuelas, tías, primas o cualquier otro familiar, tal realidad en el Código de Familia nicaragüense (2014) de forma objetiva lo retoma en el artículo 267, el que a mi parecer la redacción quedó amplia al referirse a la autoridad parental, que implica mucho más que el cuidado personal, sin embargo, regula una realidad objetiva de Nicaragua.

3. La administración de los bienes, en el caso que el hijo o hija sea titular de propiedades, derechos y acciones, los progenitores deberán asumir la administración de estos, desempeñando las funciones de un administrador de estos bienes, sin derecho a disponer de estos en cuanto a su enajenación, donación o hipoteca, debiendo en tal caso y demostrada la necesidad en beneficio del hijo o hija, solicitar en la vía judicial la autorización para poder transar al respecto.

\subsection{Alcance de la autoridad parental, titularidad y ejercicio parental}

El alcance de la autoridad parental se clasifica en: la titularidad y el ejercicio de la acción diaria que hacen los progenitores en relación con los hijos e hijas. La titularidad, tal como lo expresan Velazco (2008) y Abboud (2016), es la potestad derivada por la ley. Se atribuye por el hecho mismo de ser padre y madre, debiendo acreditarla con la debida inscripción del hijo o hija, derivando esta en los derechos-función que deben cumplir desde antes de que el hijo o hija nazca.

Este actuar diario o cuidado de la persona menor de edad es ejercido de forma conjunta cuando ambos progenitores se encuentran juntos, sin embargo, se confunde cuando existe separación de los progenitores, en la medida que se entiende que, quien ejerce el cuido personal del hijo o hija, dispone también de manera unilateral de la representación, el establecimiento de residencia y la administración de los bienes, lo que no es correcto porque estarían atribuyéndole un alcance a la función de cuido personal que corresponde al conglomerado de derechos y funciones que se derivan de la autoridad parental, titularidad conferida tanto por la naturaleza, como por la ley. 
El Código Civil y Comercial (CC y C) de Argentina reguló en los artículos del 640 al 643, de forma más específica la función de cuido cuando los progenitores lo ejercen juntos o de forma separada, dejando de manera clara y delimitada las diferentes circunstancias que se puedan derivar de la separación, lo que hace que su interpretación y aplicación sea de manera más comprensible. De tal manera que, el cuido personal corresponde solamente a una de las funciones que por sus características de contacto directo, se fortalece con el desarrollo de apegos emocionales significativos con la persona que ejerza este derecho, lo que no se debe interpretar que con ello el progenitor no custodio haya perdido todos los derechos y las funciones derivados de la autoridad parental.

Al respecto, Acuña (2015) nos aclara ese error de alcance que se presenta en casos de separación:

... en los casos de vida separada de los padres: la patria potestad era ejercida porel padre que tenía el cuidado personal del hijo, solución que se justifica en la necesidad de facilitar su ejercicio. Como consecuencia de lo anterior, el ejercicio de la patria potestad siempre era individual y constantemente le correspondía a la madre, ya fuera por la ausencia de acuerdo que otorgara al padre tal cuidado, ya fuera por la dificultad de probar en juicio las circunstancias legales que permitían alterar la atribución legal (p. 60).

Esta situación obedece a la marcada tendencia patriarcal en la que se ha atribuido el cuidado de los hijos e hijas a la madre, tal realidad era plasmada en las legislaciones para garantizar que, a una edad mínima y aunque ambos progenitores presentaran igualdad de condiciones, se iba a preponderar que fuera la madre quien ejerciera el cuido. Así se encontraba contemplada en el artículo 6 del decreto 1065 en Nicaragua. Y de igual manera lo refiere Marroquín (2010), cuando expresa que: "países como Honduras y Nicaragua, aún mantienen la preeminencia de la mujer para ejercer la función de cuidado de los hijos e hijas, sobre todo en edades tempranas" (p. 208). Este estudio el autor no lo fundamentó en el estudio en el decreto 1065 y solo hizo referencia al Código Civil. En la actualidad, el Código de familia de Nicaragua ha eliminado la preferencia mencionada por el autor.

\section{Reconocimiento de los derechos humanos-familiares de la niñez}

Los cambios sociales han reconocido a la mujer como miembro activo de la familia y de la sociedad, lo que quiérase o no trastoca las funciones que normalmente la sociedad le ha encomendado a la mujer en la distribución del trabajo dentro de la esfera de lo privado, considerando entonces meritorio hacer una referencia breve a las conquistas jurídicas que ha logrado la mujer en el plano internacional: la 
atención prestada a la mujer mediante la Convención sobre la eliminación de todas las formas de discriminación contra la mujer (en adelante Cedaw), firmada en 1979 y la Convención interamericana para prevenir, sancionar y erradicar la violencia contra la mujer llamada Belém do Pará, del 9 de junio de 1994, estos documentos humanizan los derechos desde la perspectiva de la mujer, redactándose estos en forma diferente a la androcéntrica, como lo vimos en la codificación civil nicaragüense mencionada anteriormente.

Quintero (2005) nos hace reflexionar sobre el dinamismo y la complejidad de la sociedad en el que se han desarrollado fenómenos contemporáneos que destacan el papel de la mujer, los que enumera asó: incursión global de la mujer al sistema productivo formal y al espacio público, inserción de la mujer en la formación universitaria y el hecho de que se ha convertido en una proveedora económica importante del hogar.

En la actualidad la mujer tiene igualdad en la participación de las obligaciones y los derechos en la familia, pasando de ser un objeto de protección a un sujeto de derecho. A pesar de que la mujer ha superado bastante esta brecha desigual, aún es un tema a tratar con mayor profundidad, y que por los cometidos a alcanzar en este trabajo no se aborda. Sin embargo, según el resumen ejecutivo de la Organización Internacional del Trabajo, en sus tendencias del 2016, reflejan lo siguiente: "En los países tanto de altos ingresos como de bajos ingresos, las mujeres siguen trabajando menos horas en un empleo remunerado, mientras que asumen la gran mayoría de las labores de cuidado y las tareas domésticas no remuneradas" (p. 7).

Es importante mencionar que la marcada tendencia al hecho de que la mujer sea la que ejercite el derecho de cuido y crianza de los hijos y que esta función se le niegue al padre por convencionalismos sociales, de igual manera es marcada la tendencia de que sea esta quien asuma la carga tanto emocional como material en el momento del abandono del progenitor, lo que ha llevado a que se le regule con especial atención la jefatura femenina establecida en Nicaragua en el artículo 2 del Código de Familia.

Fauné (1995) expresa esta realidad cuando expone que las mujeres: “... aparecen asumiendo el papel de gestoras y articuladoras de nuevas estrategias de manutención de la familias" (p. 2). Las características propias de la sociedad machista mezcladas con los factores socioculturales han hecho del abandono paterno justificado (migración, discapacidad o muerte) e injustificado (omisión de la obligación alimentaria y participación en el desarrollo de los hijos e hijas) que sean las mujeres tratadas duramente al asumir solo ellas toda la responsabilidad parental, asumiendo valientemente estas obligaciones de manera unitaria. A este comportamiento Fauné 
(1995), en su estudio de las familias le llama “...El problema de las condiciones desiguales en el ejercicio de la jefatura del hogar femenina” (p. 4).

Con respecto a las relaciones familiares marcadas en el machismo y el desplazamiento total de las responsabilidades familiares a cargo solamente de la mujer por la repetición de roles, Gómez (2010) expresa que:

En Nicaragua muchos niños y niñas no sólo carecen de la presencia cercana de su padre, sino también de su apoyo material para enfrentar la realidad económica en que viven la mayoría de los hogares nicaragüenses, quedando muchas veces las madres, con la total responsabilidad y cuidado de sus hijos e hijas (p. 261).

Lo observado por Fauné y Gómez constituyen elementos causales por los cuales el Estado, en procura de equilibrar la desigualdad en el cumplimiento de las obligaciones, protege la jefatura femenina, sin embargo, considero que tal normativa fomenta la desigualdad y la irresponsabilidad paterna. Con el ánimo de unir esa brecha de irresponsabilidad debería adecuarse la normativa con medidas de control de cumplimiento alimentario y de participación en la vida de los hijos e hijas, lo que sería objeto de investigación.

En relación con la humanización de los derechos de la niñez y adolescencia, encontramos que la Convención sobre los Derechos del Niño, adoptada el 20 de noviembre de 1989, reconoce a los niños y adolescentes como sujetos de derechos y que parte de grandes columnas que nos guían en el actuar tanto familiar, social y estatal. Esta triple dimensión del compromiso con respecto a la niñez y adolescencia en las aristas de este compromiso se deriva del artículo 19 de la Convención Americana sobre Derechos Humanos, en la que de forma integral se comparte la responsabilidad de la protección y garantías que se le tienen que brindar a la niñez y adolescencia.

Esta Convención aborda los derechos humanos de los niños y adolescentes desde la perspectiva de estos y no desde la perspectiva adultista, de la cual casi toda la legislación se deriva. En ella se establecen principios transversales, como el interés superior del niño, niña y adolescentes, así como el reconocimiento de la autonomía progresiva. López (2010) expone con claridad los principios que la contienen y los sintetiza en:

Principio sobre la no discriminación (artículo 2),... Principio del interés superior del niño y la niña (artículo 3),... principio sobre el derecho a la vida, supervivencia y desarrollo (artículo 6)... y respeto a la opinión del niño y la niña (artículo 12) (pp. 309-310). 
$\mathrm{Al}$ respecto y sin dejar de expresar que es un avance el reconocimiento al trabajo conjunto de ambos progenitores, la tendencia es democratizar las relaciones parentales, considerando los derechos que tiene consagrada la niñez desde la CDN. Es así que la humanización de los derechos reconocidos a la niñez y adolescencia nos instan al reconocimiento de sus competencias y capacidades, esta debe ser tomada en consideración y valorada desde los tres ámbitos: familia, sociedad y Estado, establecido este derecho en el artículo 5 de la CDN.

Estos principios reconocidos en los instrumentos internacionales especializados relativos a la mujer y a la niñez, ya habían sido identificados y plasmados desde la perspectiva androcéntrica en los instrumentos de derechos humanos anteriormente, donde podemos encontrar de forma repetida los principios de igualdad, dignidad, libertad y protección a la familia, así lo establece Villabella (2016), cuando refiere el acogimiento constitucional que hacen los países al reconocimiento de los derechos humanos en la familia, desde tres aristas: la familia, la sociedad y el Estado.

La Declaración Universal de Derechos Humanos consagró el derecho al matrimonio y a fundar familia en condiciones de igualdad, yestipuló el respeto a la vida privada y familiar. Definió a la familia como elemento natural y fundamental de la sociedad que tiene derecho a la protección de la sociedad y delEstado. El Pacto de Derechos Civiles y Políticos retomó los anteriores pronunciamientos, incorporó la obligación delEstado, la sociedad y la familia en la protecciónal menor, y refrendóelderecho de estos a ser inscriptos y adquirir una nacionalidad. El Pacto de Derechos Económicos, Sociales y Culturales reguló la protección del Estado a la maternidad, mediante el otorgamiento de licencia con remuneración o con prestaciones de seguridad social y reiteró la protección a los niños y adolescentes, la igualdad de filiación, y la protección contra la explotación económica y social de los menores (p. 39).

Tal como se ha esbozado anteriormente, la transformación del derecho de familia inicia desde el reconocimiento que los instrumentos internacionales hacen en un plano de igualdad para todos los miembros que componen la sociedad, enunciando el respeto a la libertad, a la dignidad y a la igualdad. Así lo encontramos en los artículos 1, 7, 16 y 25.2 de la Declaración Universal de los Derechos Humanos (en adelante DUDH) en la que se establecían el respeto a la dignidad e igualdad de trato de todos los individuos, el derecho a la protección y al trato igualitario sin discriminación alguna y el reconocimiento de todo ser humano a fundar una familia y disfrutar de iguales derechos en cuanto al matrimonio, desarrollo y disolución de este.

El artículo 1 de la Declaración Americana de los Derechos y Deberes del Hombre (1948) establece el derecho a la vida, a la libertad e igualdad, derecho a la 
maternidad y establece el derecho a ser escuchado en público, así como garantizar un nivel de vida adecuado. De igual manera encontramos en los artículos 3 y 19 del Pacto Internacional de Derechos Económicos, Sociales y Culturales (1966), el derecho a la protección; la Convención Americana sobre Derechos Humanos (1969) establece en los artículos 1, 8, 17, 19 y 25 los derechos humanos relativos a la familia y de forma muy importante puntualiza el derecho a la protección y que esta sea brindada desde la familia, la sociedad y el Estado.

En relación con los derechos del niño y la niña encontramos que sus derechos humanos fueron plasmados desde la perspectiva de la niñez, a diferencia de la forma en que ha sido redactada siempre la ley. En la Convención sobre los Derechos del Niño se establecieron principios fundamentales que dan lugar a desarrollar estudios al respecto. En el marco del objetivo de esta investigación se establecen como principios transversales: el interés superior de la niñez y adolescencia, el derecho a la igualdad y a la no discriminación, el derecho al reconocimiento de la autonomía progresiva en el artículo 5 y el derecho a la supervivencia y a las obligaciones derivadas de ambos progenitores con respecto a sus hijos e hijas.

Toda esta transformación sobre los derechos del niño, niña y adolescente, así como el reconocimiento de plano de igualdad y dignidad de la mujer dieron origen a que los Estados firmantes de estos tratados, adecuaran y elevaran a rango constitucional su contenido, es así que en casi todas las constituciones políticas se ha acogido el contenido de la normativa internacional. Nicaragua en los artículos 46 y 71 de la Constitución Política (1987) acoge el contenido de los instrumentos internacionales y asume el compromiso como Estado de respetar e interpretar los convenios a la luz del objeto que da origen a la norma internacional.

\subsection{Reconocimiento del niño, niña y adolescente como sujetos de derechos}

La humanización de los derechos dio origen a que los Estados internamente adecuaran sus ordenamientos jurídicos, estableciendo tanto en la constitución como en las leyes ordinarias la doctrina de protección integral de la niñez y adolescencia que nace desde esta nueva perspectiva y el reconocimiento del niño y niña sujetos de derechos, y no objetos de protección. Conocida esta última forma de relacionarse como la doctrina irregular. Esta transformación hace que nazcan nuevas codificaciones con destino y especial énfasis en la niñez y adolescencia, así como en la familia, dando origen a que se promulguen leyes especiales, o bien, que se adecúen las ya existentes.

En Nicaragua la doctrina de protección integral se encuentra retomada en el Código de la Niñez y Adolescencia (1998) (en adelante CNA), en los artículos 
$6,9,10,11,12$ y 17, y en las leyes especiales que dieron origen a dar respuestas a las demandas familiares antes de que se diera el proyecto del Código de Familia que fue aprobado en el año 2014. En este código se plasma el principio rector del derecho de familia, de interés superior, y se reconoce al niño, niña y adolescente como sujetos de derechos, al brindarles participación en los procesos tanto administrativos como judiciales, a través del derecho a brindar su opinión, lo que implica el derecho a ser escuchados de forma activa por las autoridades.

Es importante observar cómo el artículo 12 del CNA, da salida al principio de protección que encontramos tanto en los instrumentos internacionales mencionados, así como en la Constitución Política de Nicaragua (1987), que establece:

Las niñas, niños y adolescentes tienen derecho intrínseco a la vida desde su concepción y la protección delEstado a través de políticas que permitan su nacimiento, supervivencia y desarrollo integral y armonioso en condiciones de una existencia digna. La niña, el niño y los adolescentes tienen derecho a la libertad, a la seguridad, al respeto y a la dignidad como personas humanas en proceso de desarrollo y con características particulares como sujetos de los derechos establecidos en la Constitución Política y en las leyes (Artículo 12 delCNA).

Este artículo contempla los principios rectores que hemos venido marcando en el reconocimiento de la dignidad del individuo y a los otros principios que fortalecen de forma esencial al ser humano en cuanto a su dignidad, entre ellos tenemos los principios de libertad, seguridad y respeto. Consecuencia de este derecho a la dignidad y al respeto del individuo, el artículo 43 de la misma codificación establece la obligación de orientación que tienen los progenitores en el apoyo a desarrollar las posibilidades de la personalidad, aptitudes y capacidades físicas y mentales de la persona en desarrollo, expresado en el artículo 5 de la CDN y el artículo 280 del Código de Familia de Nicaragua (2014) (en adelante CFN).

Esta doctrina de protección integral en otros países ha sido acogida como elemento transformador de su régimen jurídico interno, así encontramos en El Salvador la Ley de protección integral de la niñez y adolescencia (2009), el principio de autonomía progresiva establecido en el artículo 5 de la CDN y asumida en el artículo 10 de la ley en mención, asimismo, acoge los principios generales de igualdad, no discriminación y equidad ubicados en el artículo 11, el medular principio de esta doctrina, el principio de interés superior del niño lo encontramos en el artículo 12, y devela los principios que la doctrina moderna tiende a desarrollar de forma más horizontal, estableciendo igualdad en el plano del ejercicio de las funciones de los progenitores en cuanto a la corresponsabilidad de la familia, sociedad y Estado y el de prioridad absoluta establecidos en los artículos 13 y 14 de la ley relacionada. 
Es necesario trabajar en forma conjunta a manera de bloque en los derechos derivados de la $\mathrm{CDN}$ en relación con el derecho a la igualdad, a la supervivencia y desarrollo, a la protección y a la participación. Se debe profundizar en dar contenido a los principios ontológicos que originan estos derechos; entre ellos, el derecho a la dignidad, a la libertad, a la igualdad de trato y mejor interés en el respeto al desarrollo de las competencias humanas como persona.

Nicaragua, en el Código de Familia (2014) marca un hito histórico, ya que es el primer código en la historia del derecho que nos brinda una estructuración moderna, ya que ofrece un cambio de perspectiva humanista e integrador, desde el reconocimiento de cada miembro de la familia en sus diferentes clasificaciones; con respecto al tema recoge particularidades propias de las relaciones parentales, la nomenclatura existente sufre transformaciones y pasa de relaciones madre, padre e hijos a autoridad parental, con mayor abordaje en cuanto a las realidades del país, entre ellas citamos la prohibición de la corrección física (artículo 280) y la delegación de la función del cuido de los hijos e hijas a otros miembros de la familia en el contexto ampliado, propias de la historia del país plasmadas de forma clara y precisa en el artículo 267 del CF; desarrolla además las funciones generales derivadas de la autoridad parental de cuido de la persona menor de edad, reconocimiento de la capacidad progresiva, representación, administración de los bienes de los hijos e hijas, de igual manera regula las causales de suspensión y pérdida de autoridad parental, así como las circunstancias que la extinguen. Todo se encuentra en el libro III en los artículos 268 al 300 del CFN.

En la práctica social encontramos que esas transformaciones son aceptadas a paso lento, por falta de entendimiento al alcance de los derechos de las personas menores de edad para empezar a respetarlas como personas y reconocer la evolución en su desarrollo personal. Así lo sostienen Herrera (2017) y Cillero (s.f), al referirse a la necesidad de adecuar el derecho interno al ajuste objetivo debido a la necesidad del reconocimiento de los derechos y capacidades de las personas menores de edad. Cillero remarca el tema del control del respeto a estos derechos por parte del Estado.

En ese sentido Gallego (2015) establece la dificultad en el cambio y en la participación infantil:

Laparticipacióninfantil estáestrechamenteligadaconelprotagonismodelosniños y lasniñas, quienes no soloaportan a su desarrollo y al medioqueles rodea, sinoque desempeñan el papel principal en su actuar cotidiano; sin embargo, la participación no puede ser pensada exclusivamente en términos de integración en actividades, es necesario trascender esta idea y apropiarse de la concepción de la participación 
como derecho y de las posibilidades que concede. En tal sentido, es importante el reconocimiento de sí mismo y de la capacidad de actuación dentro de los escenarios sociales, representados en la familia, la escuela y la comunidad (p. 158).

Efectivamente, debido a la transformación del derecho de familia y la desmembración de este desde su matriz, el derecho civil ha requerido que se haga un enfoque más especializado en cada miembro en las familias, desde las funciones que les son atribuidas como progenitores y desde el reconocimiento del hijo o hija como "persona" individual, lo que hace que pasemos "de una concepción tradicional, que concebía al menor un estatus de persona meramente protegida, a una concepción moderna, que le confiere, ... el estatus de persona (tendencialmente) autónoma" (p. 51), según lo afirma Rocha (2015), de tal manera que no se logra cambiar esa visión, si no entendemos el desarrollo evolutivo de las personas en crecimiento, no se logrará el respeto a sus derechos personalísimos, así lo expresan Kemelmajer (2015) y Herrera (2017), en diferentes exposiciones con respecto al tema de la capacidad progresiva y la urgente necesidad de asumir el cambio.

El cambio consiste entonces en pasar de una representación anulante en el ejercicio de la autoridad parental a un accionar más participativo mediante el acompañamiento y apoyo que los progenitores deberán brindar a las hijas e hijos, basándose en el respeto de los derechos humanos, de tal manera que los progenitores no deberán ejercitar la autoridad parental mediante el dominio y el autoritarismo, sino que corresponderán a los cambios de paradigma en el ejercicio de sus derechos de entender que mediante el acompañamiento, guía y apoyo también estarán siendo coherentes con las funciones atribuidas por la ley, de forma más inclusiva y democrática donde todos los miembros de la familia tengan derecho a opinar en las decisiones que se tomen en el hogar.

El término de autoridad parental ha recibido críticas por el significado de la palabra autoridad; Trejos, Ramírez y Benavides (2010) aclaran el sentido en que debe entenderse esta institución: "La autoridad parental no significa de modo alguno que el hijo sea propiedad de sus padres o juguete de sus caprichos sino responsables ante la ley de su deber de educación. Es lo contrario del poder abusivo" (p. 602).

Los parámetros anteriores se encuentran reconocidos en algunas codificaciones en la región centroamericana que han establecido los cambios en las funciones del ejercicio de la autoridad parental, así lo podemos observar en los artículos 186 y 187 de Honduras, artículos 206, 207 y 211 de El Salvador, artículo 316 de Panamá y en Nicaragua aunque no establece la distinción entre la titularidad y las funciones de la autoridad parental, el artículo 274 del CFN hace un listado de las tareas diarias que comprende el cuidado personal de los hijos e hijas. 
Los principios de igualdad, solidaridad y coparentalidad en el ejercicio del cuidado personal de los hijos e hijas los encontramos en el artículo 73 la Constitución Política nicaragüense, en el CC y C de Argentina, estos principios se encuentran establecidos de forma específica y moderna, tanto la titularidad y el ejercicio de la responsabilidad parental, como el cuidado personal del hijo por los progenitores y la guarda otorgada por el juez a un tercero, en los artículos 641 al 657, en estos se contemplan las diversas circunstancias que se pueden presentar en un conflicto familiar y la necesidad de regular este cuido personal de los hijos e hijas cuando existe separación de los progenitores.

El cuido y crianza personal garantiza el desarrollo integral de la niñez y adolescencia, el que se logra en actividades retroalimentantes entre los progenitores y el niño o niña y adolescente, y es en ese reconocimiento de las necesidades de estos, en la escucha de su opinión y en la participación activa en las tareas propias de la familia y de cada uno de sus miembros que se logra respetar la dignidad de la persona del menor. Herrera (2015) expresa que la tendencia moderna en la democratización de las relaciones familiares, está dada en la participación activa de la persona menor de edad en todo lo que tenga relación con su desarrollo integral en sus diferentes ámbitos, llamándole la democratización de las relaciones familiares, todo ello derivado del reconocimiento que se hace desde la CDN en su artículo 5 antes mencionado.

Encontraremos posturas que se oponen a la transición de esta institución familiar y que consideran que las relaciones democratizantes desautorizan la autoridad que los progenitores históricamente han ostentado en relación con sus hijos e hijas. Observemos lo que dice Loyarte (2015):

Esta es la transición que experimentan las relaciones filiales en la postmodernidad, un nuevo modelo de vida que restructura los patrones socialmente interactivos entre quienes dicen ser padres e hijos, uno que cuestiona la vara de la instrucción, el régimen penitenciario familiar, laidentidad histórica y las preferencias del hijo,y más. La responsabilidad parental, a su vez, justifica otras instituciones jurídicas como la custodia compartida, el cumplimiento insoslayable de la asistencia económica (entra al debatela prisión por deudas alimenticias), laexpansión social del Derecho deFamilia y lacapacidad progresiva de los niños y adolescentes para autodirigirse como sujetos y no ser dirigidos como objetos (pp. 34 y 35 ).

El análisis que hace el referido autor, se basa en lo establecido en el artículo 206 del Código de Familia de El Salvador (1994), que básicamente establece las tres grandes funciones de cuido y crianza, la representación y administración de bienes, sin embargo, alega que las relaciones parentales se extienden socialmente más allá 
del marco de la ley e involucran siempre instrumentos de poder en el seno de la familia y delimita diferencias en la sociedad.

La función a desarrollar en relación con el respeto de la dignidad y la capacidad progresiva de los hijos e hijas, desde el desglose de las funciones en el ejercicio diario de esa función se centra en el cuido y crianza de la persona menor de edad.

La función de cuido y crianza, desde la perspectiva de los derechos humanos, se desarrolla en el diario vivir mediante el acompañamiento, guía y apoyo que hacen los progenitores, garantizando los derechos fundamentales en la medida en que los NNA avanzan en edad y capacidad evolutiva, así como el desarrollo de la madurez estos; los derechos humanos se encuentran dotados de todas las condiciones necesarias de acuerdo con el estatus de cada familia para que se vayan desarrollando como personas, como individuos garantizando la integridad física, sicológica y emocional. Esta obligación también se encuentra establecida en el artículo 18 de la CDN, que establece la función de crianza y educación. El reconocimiento de las facultades progresivas de la persona menor de edad se individualiza de acuerdo con las particularidades y características personales de cada individuo y conforme al ambiente social donde el NNA se ha desarrollado.

LaCDNestableceunanuevaforma de ejercitarlafunción delcuidadopersonal en la persona menor de edad, de manera tal que los progenitores en el ejercicio de la autoridad parentalhagan una correctarepresentación de los derechoshumanos de sushijos e hijas mientras ellos desarrollan sus competencias y no actúen de forma anulante, sustituyendo los derechos de estos a conveniencias de las circunstancias que sele presentan. Consecuentemente, la CDN expone la necesidad de erradicar esa práctica abusiva de la representación de los padres, de invisibilización de la persona del hijo o hija, desde el hogar familiar debiéndose escuchar activamente la opinión de estos, en las conversaciones de familia o toma de decisiones del hogar, de acuerdo con su edad.

Herrera (2017) expresa que establecer la edad es una tarea difícil para los legisladores, porque el desarrollo de cada niño o niña depende de muchos factores, muchos de ellos sociales, por ejemplo, la capacidad progresiva de un niño de la calle para defenderse no es la misma que la capacidad progresiva de un niño que no ha vivido tales circunstancias; en el mismo plano, la capacidad progresiva de un niño que se ha desarrollado en el seno del hogar donde se le ha garantizado educación, tendrá desarrolladas mejores competencias en esa área que el niño en situación vulnerable. 
La CDN señala un desafío nada fácil, pero necesario para la adecuación de los tiempos. Se debe iniciar con el reconocimiento del derecho del niño o niña a participar activamente de su propio desarrollo y del desarrollo familiar, ayudándoles a crecer y a identificar sus cualidades y competencias para la vida, aceptándolos como otro miembro de la familia, tomando en cuenta el desarrollo de estas competencias para su autonomía como tal; así asumió Argentina, en el artículo 26 del CC y C, el reconocimiento de esa autonomía progresiva, con ayuda multidisciplinaria en caso de ser necesario; Nicaragua lo asume de manera general en el artículo 280 del CFN (2014). Es en el seno del hogar donde se identifica la autonomía y es el ambiente propicio donde se debe desarrollar el respeto por el ser humano en crecimiento, colaborando ambos progenitores en el desarrollo de las competencias de las hijas e hijos para la vida.

Para lograr alcanzar lo que nos proponen los derechos humanos de los NNA planteados en la CDN, se deben reconocer los derechos personalísimos que tienen estos, los que consisten en la libertad, la igualdad de trato y la dignidad. Lo que nos guiaría a cambiar la actitud y el trato para con ellos, debiendo aprender a tratar y respetar al hijo o hija como "otro Yo".

\subsection{Derechos personalísimos de la niñez y la adolescencia}

\subsubsection{Derecho a la dignidad, la libertad y capacidad progresiva de la niñezy adolescencia}

La dignidad como un derecho a reconocer en un plano de igualdad en el ejercicio diario de la autoridad parental en relación con la persona en desarrollo es necesario entenderla, para comprenderla y respetarla. Nordenfelt (2014) hace una clasificación de dignidad desde la perspectiva individual y humana:

... distingue cuatro significados del término dignidad. Tresde ellos son relativos, o noesenciales:ladignidad comomérito(referidaalaespecial situacióndelapersona enla sociedad), la dignidad comoestatura moral (dependientedel comportamiento de la persona), y la dignidad de identidad (más difícil de definir, se refiere a aquella dignidad que reconocemos en nosotros mismos, enraizada en nuestra historia y en la relación con los demás; puede sufrir alteraciones por vejaciones o malos tratos por parte de otros, o también en algunas enfermedades). En estas tres acepciones, la dignidad admite un crecimiento, una disminución, o incluso la pérdida por parte del sujeto del que se predica (p. 246).

El autor continúa con su clasificación y en esta última pone especial énfasis en su permanencia e inamovilidad como derecho, puesto que no admite modificación. 
Parafraseando estos significados se anexa el concepto de la dignidad humana, que es un tipo de dignidad completamente diferente, que poseemos los humanos en cuanto personas: no puede perderse ni admite gradación alguna. "Esta faceta de la dignidad se refiere a la dignidad que poseen todos los seres humanos por igual por el hecho de ser seres humanos, y es entendida como un valor específicamente humano, que no le puede ser arrebatada a la persona mientras viva, ...Constituye la base de nuestros derechos humanos básicos y por ello, ninguna persona puede ser tratada con menos respeto que otra" (p. 247). La fuente jurídica de esta dignidad la encontramos en el artículo 1 de la Declaración Universal de los Derechos Humanos (1948).

En esta cita se hacen diferentes acepciones de la palabra dignidad, encontrándose íntimamente relacionada con el contexto social a las que les llama relativas. Esta tiene que ver con el respeto de la persona humana, a esta última no la denomina, pero según mi criterio le podría llamar absoluta. En tanto que su aporte tiene el objetivo de direccionar identificando la individualidad de las personas en crecimiento.

Melendo (2010) nos explica las singularidades que cada uno tiene como persona:

La palabra "persona" expresa, por tanto, la individualidad del individuo, su autonomíay distinción respecto al resto de lo existente, pero de forma no definida. En este sentido, "persona" indica a un singular muy singular, aunque indiscriminadamente. Es decir, a cada uno de los sujetos personales, en cuanto muy individuos, pero de manera general o inconcreta: individuum vagum, según la expresión latina (p.57).

Por tanto, la unidad de la familia no debe entenderse como las características propias en su conjunto, sino del respeto de las individualidades de los miembros que la componen, tiene diferentes características sociales que la identifican como tal, aunque no deja de tomar valor el contexto social en que se desarrolla y la impresión de los valores que se aprenden en el seno del hogar. La idea es advertir que los hijos e hijas que aún no han alcanzado la mayoría de edad, son individuos que requieren que se les reconozca su dignidad humana como personas singulares y que no necesariamente se tienen que desarrollar características homogéneas a los progenitores u otros miembros de la familia.

\subsubsection{Reconocimiento de la progresión de las facultades de la persona menor de edad (la capacidad progresiva)}

Partiendo de la vertiente de derechos humanos que establece el reconocimiento de la autonomía progresiva de los NNA, las legislaciones más modernas, como en Nicaragua, y aún más desarrolladas como en Argentina, han acogido en la normativa interna el nivel de reconocimiento de la autonomía progresiva de estos, en la 
medida que en la normativa se ha plasmado de manera clara y precisa el derecho a ser oído: artículo 12 de la CDN, artículo 17 del CNA, artículos 440, 448, 449 del Código de Familia de Nicaragua y de manera especial se recoge el contenido en el artículo 5 de la CDN y en el artículo 280 del CF. Ampliamente explicadas en observaciones generales No. 4, 7, 12, 14 y 17 del Comité de los Derechos del Niño.

Argentina, actualmente un referente latinoamericano en relación con los temas familiares, regula en los artículos 26 del CC y C de manera específica los alcances de la participación, y autonomía progresiva aplicada del desarrollo de los adolescentes:

Artículo 26. Ejercicio de los derechos por la persona menor de edad. La persona menordeedad ejercesus derechosatravésdesus representanteslegales. Noobstante, la que cuenta con edad y grado de madurez suficiente puede ejercerpor sí los actos que le son permitidos por el ordenamiento jurídico. En situaciones de conflicto de intereses con sus representantes legales, puede intervenir con asistencia letrada. La persona menor de edad tiene derecho a ser oída en todo proceso judicial que le concierne así como a participar en las decisiones sobre su persona.

Este artículo reconoce con ello la capacidad progresiva de la persona menor de edad. A pesar de que la extensión moderna de decidir sobre temas de salud que comprometen la vida, me parece un tanto riesgoso a simple vista. Sin embargo, encuentra la salida en la medida que expresa que todo se resolverá de acuerdo con el interés superior de los menores de edad considerando la multi-disciplinariedad, es decir, la opinión médica.

En un conflicto familiar en el que se involucra a un NNA, Herrera (2016) nos expone la necesidad de hacer un abordaje multidisciplinario:

La interdisciplina, íntimamente vinculada, permite advertir el proceso de madurez del niñoen elcaso concreto.Es sabidoqueincidenfactoresdetipobiológico,psicológico y social, y que aquel varía conforme la edad, el nivel de estímulos y el marco social, económico y cultural en el cual se desarrolla cada niño, pero de ninguna manera podrían trazarse reglas generales y mucho menos absolutas frente a una realidad tan dinámica como la de nuestra sociedad tan cosmopolita (p. 18).

Este abordaje nos da pauta para afirmar que las demandas de los conflictos familiares ameritan respuestas multidisciplinares apoyándose en la colaboración necesaria de la psicología, medicina, trabajo social, genética, reguladas en las funciones de disciplinas auxiliares. 
En cuanto al derecho a ser tomado en cuenta en la familia, la sociedad y en los procesos, Famá (2016) expone en videoconferencia que “... las responsabilidades parentales deben darse desde una relación trial Estado, familia y niños, debiendo reposar la capacidad progresiva en la necesidad de equilibrio". Este derecho se positiviza en la medida que el ordenamiento constitucional e interno asume los derechos humanos establecidos en la Convención Internacional sobre los Derechos del Niño.

El CFN establece principios rectores y principios especiales tanto para el derecho personalísimo de los miembros de la familia como en el cambio de procedimiento y de comportamiento sociales, entre otras muchas ventajas que establece. En estos artículos encontramos plasmada la orientación emanada de los derechos humanos y acoge de igual manera el respeto a la autonomía de desarrollo particular de cada ser humano en la familia. Todo ello implica un gran desafío desde las tres dimensiones, familiar, social y estatal, en las políticas públicas y en la interpretación y aplicación a la normativa.

Argentina en el nuevo CC y $\mathrm{C}$ acoge la postura mixta, según lo enuncian en los artículos 23, 24, 31, 639 y 645, ya que la autonomía reconocida a la persona menor de edad, requiere del apoyo multidisciplinario en casos concretos, de tal manera que no es absoluta. Nieto (2016), también expresa que la capacidad progresiva de los NNA va a estar en dependencia del requisito del consentimiento, que para que pueda ser válido se requiere que la persona que lo emite tenga la madurez suficiente o las facultades mentales adecuadas para poder decidir con libertad.

Nicaragua reconoce la participación de la niñez y adolescencia en las relaciones familiares y en la capacidad de ejercicio en diferentes acciones, que encontramos reguladas en los siguientes artículos: 22, 54, 167, 221, 255, 272, 280, 287, 301,302, 304, 322, 378, 448 y 484 del CFN. Es importante destacar que la participación en los procesos no garantiza que los NNA sean escuchados por la autoridad con efectividad, es así que Herrera (2016) remarca el término "escuchar" por sobre el de "oír", pues es más que esto último lo pretendido:

Escuchar es percibir, empatizar, observar, saber, preguntar, relacionar, analizar, distinguir lo manifiesto de lo latente, lo que aparece de lo que es; poder integrar lo oído con el juego de relaciones que conforman la dinámica de una particular familia (p. 19).

Nótense las acciones que involucra la escucha activa, quedará cuestionarse si, como autoridades, tanto administrativas, así como judiciales cumplen en garantizar el derecho a la participación en esas acciones en mejor interés del NNA y si la 
escucha es activa, aplicándola en la racionalización de las posibles consecuencias que se deriven de las decisiones que se tomen en casos concretos.

Para ello, hay que tomar en consideración el contexto en que el NNA se desarrolla y la imperiosa necesidad de entender el ejercicio de la autoridad parental desde el accionar de acompañar, guiar y apoyar a los hijos e hijas, reconociéndoles avances en sus capacidades, sabiendo que en la medida que progrese en estas, la guía de los progenitores va disminuyendo, así lo sostiene en su exposición Kemelmajer (2016), por lo tanto, no se trata de ejercer una relación parental desde la autoridad o la potestad de forma lineal y jerárquica que implica desventaja para los hijos e hijas menores de edad en relación con sus padres, entendida como ordenar-obedecer, sino desde una óptica relacional, democrática, inclusiva y participativa de todos los miembros de la familia.

En relación con la capacidad progresiva, si no se logra ver a los NNA, como individuos con características diferentes a las de sus progenitores y los otros miembros de la familia, se estaría aplicando la tendencia de nulificación y violación a los derechos personalísimos de estos. Estas son imposiciones y prácticas arraigadas de la forma en que se ejercía la patria potestad anteriormente, donde la expresión de los hijos e hijas no era valorada por los progenitores demostrando poco interés a la opinión de estos en el seno del hogar, lo cual denotaba un vacío en la escucha activa, práctica que aún no se ha erradicado.

La Corte Interamericana de Derechos Humanos (en adelante CIDH) se ha pronunciado sobre la capacidad progresiva de los niños, niñas y adolescentes; así se evidencia en los casos: Atala Riffo y Niñas vs. Chile. Fondo, Reparaciones y Costas, sentencia de 24 de febrero de 2012; y, García y Familiares vs. Guatemala. Fondo, Reparaciones y Costas, sentencia de 29 de noviembre de 2012, párr. 183. También en el caso de Gelman vs. Uruguay. Fondo y Reparaciones, sentencia de 24 de febrero de 2011, párr. 129. En este último, como muestra de todos los casos citados, sostiene la referida Corte:

En el caso de los niños y niñas, si bien son sujetos titulares de derechos humanos, aquéllos ejercen sus derechos de manera progresiva a medida que desarrollan un mayor nivel de autonomía personal, por lo que en su primera infancia actúan en este sentido por conducto de sus familiares (párr. 129).

El desarrollo humano de cada individuo se va dando de manera diferente en dependencia de sus características personales y del contexto social en que se desarrolla, la doctrina le llama autonomía progresiva como principio identificante 
en cada persona menor de edad, así lo sostienen Herrera (2017), Kelmelmajer (2015) y Cillero (s.f.).

Es así que recobra vital importancia el hecho de que los progenitores puedan determinar la singularización de cada ser humano que debe y tiene la necesidad de desarrollarse como tal en ese ecosistema, parafraseando lo que dice Rocha (2015), que la libertad, la dignidad, el respeto de la persona, la autonomía de cada ciudadano, son incompatibles para la interpretación de la patria potestad y sus funciones, por lo que la institución tiene que dinamizarse y adecuarse a los tiempos, humanizando las relaciones familiares en la medida que se toma en cuenta a las personas menores de edad en las decisiones de la familia y en las individuales de cada ser. Kelmelmajer (2015) puntualiza:

Esta categórica afirmación es hoy posibleporquelaCorte IDH, aligualquelaCorte Suprema de la Nación Argentina y el Tribunal Europeo de Derechos Humanos, adhiere al método de interpretación dinámica que, entre otras ventajas, evita la pronta obsolescencia de los textos. En este sentido, el tribunal regional reiteradamente pronuncia la siguiente fórmula: "Los tratados de derechos humanos son instrumentos vivos, cuya interpretación tiene que acompañar la evolución de los tiempos y las condiciones de vida actuales". Funda este modo de interpretar, entre otros argumentos, en el artículo 29 de la Convención Americana y en las disposiciones de la Convención de Viena sobre el derecho de los tratados (p. 49).

Es así que la tendencia de la democratización tal como la plantea Herrera (2015), es un desafío constante para el derecho de familia, ya que amerita cambiar la conceptualización de las relaciones parentales, respetando el misterio y singularidad que encierra en sí misma la persona, desde lo que esta significa para sí misma y para sus derechos, así lo describe Melendo (2013) cuando dice: “... todo esto resulta decisivo en cualquier relación que se pretenda inter-personal, explicando lo que antes ya sugería: que si no las tratamos en su estrictísima singularidad, no nos podemos relacionar realmente con las personas en cuanto personas" (p. 62).

La meta es reconocer al niño o niña desde la familia con sus propias características y singularidades como individuo, y adecuarse a los tiempos en la nueva dinámica familiar, en la aceptación del desarrollo de sus competencias. Rocha (2015) lo describe de una forma muy humana y familiar al decir:

Es únicamente en la familia donde el ser humano es o debería ser absolutamente aceptado por sí mismo y no únicamente a condición de que sea considerado inteligente o simpático, además posiblemente en la historia personal de cada uno la 
influenciamás importantesealapropiciadaporlafamilia....Enlafamiliaseaprende el valor esencial de la persona individual y de la sociedad al mismo tiempo (p. 10).

Es entonces en el seno familiar el primer lugar donde se le debe respetar a la persona menor de edad y aceptar con sus características y singularidades; por su parte, los progenitores son llamados a dinamizar sus estilos de ejercitar el cuido y crianza adecuados a la normativa, en respeto a la libertad y dignidad de la persona del hijo o hija.

\section{Criterios de valoración en el reconocimiento de los derechos humanos de la niñez y adolescencia en la perspectiva judicial}

\subsection{Interés superior de la persona menor de edad (ISN)}

Los contenidos de los artículos relacionados con el reconocimiento del desarrollo integral de los menores de edad encierran en sí mismos el principio de interés superior del menor, establecido en toda la CDN en los artículos 3 al 6. Estos por su propia naturaleza son de conceptualización indeterminada, por lo que no se debe abstraer su interpretación en los casos concretos, según nos aclara la observación general número 12 en el párrafo 52.

Cardona (2013) nos ayuda a comprender el espíritu de este principio y nos ubica en las intenciones que tiene, prevaleciendo el reconocimiento a la persona menor de edad en circunstancias diversas, como el principio y fin del sistema de protección, determinados en los artículos 3 y 12 de la CDN. De igual manera Torrecuadrada (2016) explica que la indeterminación del principio de ISN hace complicada su aplicación que, por ende, se caracteriza por ser dinámico para que pueda adaptarse en distintas circunstancias concretas, resolviendo a favor de la persona menor de edad y considerando el contexto en que se aplican.

La Corte Internacional de Derechos Humanos ha establecido los criterios de interpretación en armonía con el interés superior de la persona menor de edad, garantizando siempre el conglomerado de derechos establecidos en la CDN, en circunstancias concretas como la detallada en el Caso de las Niñas Yean y Bosico vs. República Dominicana, sentencia del 8 de septiembre de 2005, párr. 134. Este Tribunal ha señalado que revisten especial gravedad los casos en que las víctimas de violaciones a los derechos humanos son niños:

La prevalencia del interés superior del niño debe ser entendida como la necesidad de satisfacción de todos los derechos de los menores, que obliga al Estado eirradia 
efectos en la interpretación de todos los demás derechos de la Convención cuando el caso se refiera a menores de edad. [...] (p. 20).

Con respecto a este principio regulador del interés superior del niño que guía toda la esfera social, Ordeñana (2016), hace una referencia en una sentencia de la corte colombiana C - 172 del año 2004, que en su parte considerativa determina los fundamentos del principio:

Lasrazones deesa protección, se resumenen:i)el respetoaladignidad humanaque, comoloseñalalaConstitución, constituyeunode losfundamentosdelEstadoSocial deDerecho;ii) suindefensióno vulnerabilidad, porcausa del procesodedesarrollo de sus facultades y atributos personales, en su necesaria relación con el entorno, tanto natural como social; y iii)elimperativode asegurar unfuturo promisorio para la comunidad, mediante la garantía de la vida, la integridad personal, la salud, la educación y el bienestar de los mismos (p. 62).

Se hace notorio el compromiso del Estado donde los intérpretes del principio hacen la sentencia de manera muy objetiva y clara. Desde mi punto de vista plasma los derechos humanos que de manera obligatoria deben ser protegidos por la comunidad, en este sentido yo le agregaría las aristas de las tres dimensiones, la familia, sociedad y Estado cada una asumiendo sus responsabilidades. La familia como el entorno primario donde al niño se le puede dotar naturalmente, Rocha (2015) le llama como "...el medio natural para su crecimiento y bienestar", de esta simple acotación se observa el primero, el respeto a la dignidad en el reconocimiento de la autonomía progresiva y en cuanto a bienestar implica la aplicabilidad del principio de protección desde el seno del hogar.

El principio de interés superior del niño o niña ha dado pautas para que especialistas en el tema le dediquen tiempo y desde su indeterminación se busque cómo unificar los criterios de aplicación propuestos en este caso por la doctrina, de tal manera que Simón (2013) nos propone criterios de interpretación que nos marcarán las pautas a seguir para su aplicación, señalando para tales efectos los criterios "de prioridad,... de garantía,... informador,... de integración,... y de interpretación" (p. 179). Estos criterios estudiados por el autor se encuentran contenidos también en las observaciones generales no. 12 y 14, que establecen la forma en que debemos interpretar el interés superior del NNA, la forma en que debemos adecuar el ambiente para que los NNA tengan la información necesaria que le atañe a cualquier aspecto de su vida y la garantía de que estos sean tratados como sujetos de derecho en el proceso, brindando la representación ya sea por medio de sus progenitores o sus representantes con el fin de lograr una efectiva tutela. 


\subsection{Flexibilidad y dinamismo en la interpretación jurisdiccional, escucha activa}

Los criterios jurisdiccionales toman en cuenta el interés superior del niño y adolescente de una forma flexible y dinámica, de modo que posibilite la toma de decisiones para las autoridades, tomando en consideración en caso concreto, la participación activa de la persona menor de edad, con el nombramiento de su defensa técnica, cuando está ante tribunales, donde el hacer valer sus derechos puede resultar antepuesto a los intereses de sus progenitores; en el desarrollo de los procesos tanto administrativos como judiciales se debe considerar la voluntad del NNA, sus deseos, sentimientos en función de su edad y entendimiento o grado de madurez, en el factor externo, que se le pueda garantizar la estabilidad emocional de la niña, niño y adolescente, evitando la variación que le pueda perjudicar, por ejemplo, un cambio de lugar de estudio, residencia y actividades que se realizan, de igual manera hay que considerar, el sexo, la raza y las costumbres propias del lugar.

Ortega (2002) logra identificar en la práctica criterios de aplicación considerados desde otras disciplinas auxiliares como la psicología y el trabajo social que en informes periciales derivan en observar criterios de estabilidad, participación y protección adecuada que brindan los progenitores o cualquier persona que ejerza el cuidado personal del NNA, en la búsqueda de satisfacer sus necesidades de acuerdo con la edad que estos tengan (pp. 90-91).

En los criterios relacionados por el autor, revela la práctica de los principios rectores de la doctrina de protección integral que nace a partir de la CDN, el principio de protección, la participación por medio de la expresión y el de garantizar el desarrollo integral en un ambiente estable, parámetros que de igual manera deben considerarse en la toma de decisiones de las autoridades.

El principio de protección brinda la oportunidad que los NNA como sujetos de derechos sean intérpretes de su propio interés y que puedan ser escuchados de forma activa por las autoridades, debiendo ser valorada su opinión de manera cualitativa y en atención a la progresión de sus facultades y competencias de su capacidad progresiva para la adopción de decisiones familiares que sean objetivas y garanticen la efectividad de la tutela jurídica que se pretende. Es importante denotar que en la praxis de este principio se logran conjugar los demás principios que se han desarrollado, el interés superior del niño y la autonomía progresiva (artículos 3 al 6 de la CDN), así como el derecho a ser oído establecido en el artículo 12 de la CDN, en Nicaragua se establece en el artículo 17 del CNA y en el artículo 448 del CFN. Hay que mencionar que el éxito de la garantía de los derechos del NNA, va a depender en gran medida del conocimiento que tenga la persona que administre justicia y de su capacidad de análisis desde los derechos humanos de los niños, 
valorando su escucha de acuerdo con los criterios orientadores, para ello la CIDH, en la opinión consultiva No. 17, orienta la necesidad de diferenciar en los grados de discernimiento del NNA y recomienda que "debe matizarse razonablemente el alcance de la participación del niño con el fin de lograr la protección efectiva de su interés superior objetivo último de la normativa de Derecho Internacional de los Derechos Humanos en estos dominios" (párr. 101 y 102).

Los NNA deben ser escuchados aun cuando exista acuerdo entre los progenitores en cuanto a resolver el cuido y crianza de estos, ya sea que acudan a la sede administrativa o a la vía judicial para buscar conciliación. La competencia en los temas de cuido y crianza también fue conferida a la sede administrativa el poder conciliar lo relativo al ejercicio y a las formas de relacionarse con el progenitor o la progenitora que no ejerza el cuido directo de los hijos e hijas, sin embargo, en la práctica, según mi experiencia, no siempre es tomada en consideración la escucha de los NNA, ni en los acuerdos alcanzados en el trámite conciliatorio en ambas sedes, ni en las sentencias que homologan estos acuerdos, aunque el examen de garantías que realiza la autoridad judicial al alcanzar acuerdos en audiencias o bien al solicitar la homologación de estos en materia de alimentos, garantiza el respeto de los derechos de los NNA, lo que quizás hace que se releve la presencia de estos ante los acuerdos.

En algunos acuerdos los progenitores establecen como parte del contenido de estos que sean escuchados los hijos e hijas y que respeten su opinión al respecto, de igual manera acuerdan someterse de forma voluntaria a terapias que les ayuden a restablecer una buena comunicación y relaciones familiares. En otras legislaciones como en Cuba y Colombia, se les ha delegado competencia a los notarios para hacer acuerdos, al respecto Pérez (2015) nos advierte que siempre en estos acuerdos notariales se debe considerar los principios inherentes a la persona menor de edad:

... en definitiva, es el notario quien autorizará la escritura en la que se contiene la disolución del vínculo matrimonial y por ello a él le compete calibrar el cumplimiento no solo del principio de la legalidad, sino sobre todo de la protección del interés superior del menor" (p.484).

Lo expresado por el autor nos alumbra el camino que se tendría que seguir en Nicaragua para cuando se hagan acuerdos notariales, no necesariamente en acciones de cuido y crianza, que el Código de Familia no lo permite según el artículo 159, sino también en acuerdos relativos a alimentos. En Nicaragua es permitido acordar sobre alimentos en sede notarial para su posterior homologación, conforme a los artículos 321 y 326 del mismo código. La homologación judicial de acuerdos notariales es permitida en Chile y España. 
En la competencia judicial el criterio multidisciplinario de las ciencias auxiliares como la psicología y el trabajo social y en algunos casos particulares la ciencia médica, son determinantes para lograr un mejor entendimiento de los hechos y las circunstancias específicas en cada caso, consecuentemente si una decisión judicial se basa solo en la interpretación jurídica que haga la autoridad judicial, en derecho de familia, quedará escasa y su aplicabilidad será ineficaz porque no se tomó en cuenta objetivamente el entorno social en que el niño, niña y adolescente se ha desarrollado ni tampoco los indicadores de riesgos del entorno.

La forma adecuada de hacer la entrevista a la persona menor de edad también insta a las autoridades judiciales a actuar con respeto a la dignidad de esta con la prudencia debida, no debiendo tratar al niño o niña con rudeza, o en menosprecio por su condición de edad, sino que se debe de manera preambular aclarar dónde se encuentra, por qué se encuentra hablando con la autoridad judicial, se le explica con palabras sencillas cuál es la acción que instan sus padres y la argumentación sencilla que cada uno da de sus hechos, se le hace conciencia que el estar presente en ese momento ante la jueza o juez, se debe al ejercicio de su derecho humano a ser escuchado, se le aclara que lo que diga se plasmará por escrito y que ayudará en gran medida a la toma de decisiones según la valoración que se haga.

No es conveniente que al niño o niña, se le pregunte de forma tajante y directa, ¿con qué progenitor quiere vivir?, menos correcto será que una autoridad judicial plasme en el contenido de su sentencia que "el niño o niña decidió", esto es atropellante a la dignidad de la persona del niño o niña y a la extrapolación de responsabilidades, que pasa en el primer plano de los padres a los hijos e hijas y ahora de la autoridad judicial al niño o niña delegando sobre sus hombros las responsabilidades de resolver el conflicto.

Este tipo de decisiones deriva en el NNA conflictos de lealtad para con uno de sus progenitores, lo que puede desencadenar en maltratos futuros en su contra por el progenitor no escogido por el hijo o hija. De igual manera las autoridades judiciales deben considerar que la aplicación de los principios de mejor interés, de participación en la opinión del NNA, y del reconocimiento de la autonomía progresiva, no es de sencilla aplicación, porque requiere siempre de tener las competencias suficientes para poder brindarle a la persona menor de edad, estos derechos a discreción de la judicial, de acuerdo con la edad, la que en Nicaragua es obligatoria su escucha a partir de los 7 años, sin embargo, hay que cuidar que esa discrecionalidad que otorga la ley antes de la edad mínima de escucha no se convierta en arbitrariedad del derecho de los NNA, es por ello que la CDN no establece edad para la escucha de la opinión de estos. 


\subsection{Criterios de valoración desde la perspectiva judicial}

En la necesidad de observar si las autoridades judiciales están asumiendo la función de valorar de manera objetiva la participación de los NNA en el proceso, se procedió a hacer un estudio a 26 expedientes de primera instancia tomando tres de doce juzgados de Distrito de Familia de Managua en el año 2016, en los que se demandaba cuido y crianza por uno de los progenitores, o bien, por un familiar. Con el fin de observar los criterios judiciales de valoración de la escucha y consecuentemente el derecho a la participación, el resultado fue el siguiente:

Del $100 \%$ de la muestra, solamente 4 sentencias, que equivale al $15.38 \%$ de los NNA fueron escuchados de manera directa por la autoridad judicial, es decir, sin ayuda del profesional de psicología, de estas 15 sentencias equivalentes al 57.69\% de casos fueron analizados por los peritos auxiliares en psicología y trabajo social; es decir, los NNA fueron escuchados de forma integral y multidisciplinaria por la psicóloga que fue asignada al caso para identificar problemas en las aptitudes de los progenitores, o bien, para determinar cuál de los progenitores ha desarrollado mejor sus competencias de parentalidad para el acompañamiento debido a los hijos e hijas con el fin de que estos logren desarrollarse como personas. Para determinar la tendencia de personalidad aplican instrumentos y herramientas adecuados, los que emiten resultados tendenciales acerca del tipo de personalidad de cada progenitor, al final del informe concluyen con los hallazgos y recomiendan medidas o sugerencias para ayudar al miembro de la familia que lo necesite.

De toda la muestra solamente 8 sentencias, que equivale al 30.76\%, terminan en acuerdos entre partes, en los cuales no se tomó en consideración la necesidad de escuchar a los NNA, de igual manera no se tomó en consideración lo expresado en el informe psicosocial a pesar de que este ya se encontraba agregado en el expediente judicial. De la sentencia que nace del contenido de los acuerdos alcanzados en audiencias, o bien, de la solicitud de homologación que peticionan a la autoridad judicial, no se observa en el contenido de la sentencia que se relacione y valore la escucha del NNA realizada ante el equipo del consejo técnico asesor, invisibilizando la expresión de estos en la decisión tanto de los progenitores como de la autoridad judicial.

Con los resultados anteriores se podría concluir que existe una tendencia en las autoridades judiciales de no valorar la opinión del niño o niña en algunos juicios, ni en los acuerdos alcanzados por las partes. La actitud de los progenitores de acordar sin tomar en consideración a los menores de edad deriva en invisibilizarlos, sin tomar en cuenta su opinión, especialmente cuando los acuerdos alcanzados presupone beneficios para los hijos e hijas, sin embargo, retomando lo que dicen 
los doctrinarios habría que ver las singularidades y competencias que tiene cada hijo o hija para ver si el plan o acuerdo de los padres es coincidente con su particularidad. Ejemplo de ello, padres que exceden con clases extracurriculares que de paso violentan el espacio individualizado de estos, y en cierta medida la relación parental con el progenitor que no ejerce el cuido directo. De lo acordado por las partes se establece que un $53.8 \%$ de las sentencias acogen en su contenido los acuerdos alcanzados.

En cuanto a la valoración de la escucha solamente tres sentencias, que equivale al $11.54 \%$ de los casos, en su parte considerativa valoran lo expresado por el consejo técnico asesor, haciendo mención de que existen estudios al respecto y que de este se consideró la expresión de los NNA, sin mayor estimación al respecto. El $38.46 \%$, que equivale a 10 sentencias, hace una coherente relación en la motivación considerando el informe pericial psicosocial. No así las restantes, el 7.64\%, que solo relacionan en sentencia la orden girada al consejo técnico asesor, sin mencionar la opinión del NNA.

Podemos comprobar con este pequeño análisis que solo el $38.46 \%$ aplica correctamente la argumentación y motivación en relación con la escucha del NNA. Lo que refleja que aún no se ha asumido con conciencia y responsabilidad la aplicación de los principios y derechos derivados de la CDN, así como lo establecido en el régimen jurídico interno nicaragüense que acoge la doctrina de protección integral de los NNA como sujetos de derechos. Además de observarse carencia en la aplicación de criterios de interpretación en cuanto a la realidad objetiva y circunstanciada vivida en el caso concreto por el NNA a quien se le pretende tutelar de forma efectiva su derecho.

De las 11 sentencias en que se deriva la falta de escucha de los NNA, se encontró que 6 de estos expedientes reflejaban como sentencias, autos de cierre por inadmisibilidad es decir por defectos en la demanda y 5 expedientes con autos archivando la causa por falta de presupuesto procesal, a pesar de haberse advertido por la autoridad acompañar los documentos que hacían falta o brindar mayor detalle en la dirección para notificaciones, pero más allá de eso llama la atención que repercute sobre las estadísticas la forma errónea en que se registran estas causas, lo que será materia de estudio como una de las desventajas del sistema automatizado, la actitud de la persona que administra justicia y la falta de control de calidad en las sentencias.

Esta situación da origen a que se estudien y apliquen las nuevas formas de interpretación y argumentación nacidas de la humanización de los derechos de los NNA. Es importante tomar en consideración los criterios que establece Simón (2013) ya 
referidos anteriormente y que vale decir serían buenos indicadores a seguir para el desarrollo de guías de buenas prácticas o protocolo respecto del tema de aplicación del derecho a participar en los procesos que atañen a la vida de los NNA y que requerirá de una ruta a seguir para la valoración de esa escucha con un cambio de visión en el actuar jurisdiccional, considerando los derechos de estos de forma prioritaria, garantista, con información adecuada a la edad de los NNA, logrando que se integren de forma activa en el proceso y procurando hacer una correcta interpretación de sus sentimientos, afectos, emociones, con el objeto de decidir de forma objetiva y particular lo que sea más conveniente para estos.

Es importante realizar un cambio de paradigma para transformar la perspectiva en que aplicamos las funciones delegadas de la autoridad parental y la existencia de principios de interés superior del NNA y de autonomía progresiva que por su naturaleza son transversales en el derecho de familia, y que por su abstracción no se encuentran conceptualizados ni los instrumentos internacionales ni las codificaciones que los conceptualizan. Cardona (2013) nos orienta en relación con la forma en la que transversalmente debe aplicarse e interpretarse el interés superior del niño, como principio, como derecho y como norma de procedimiento, de tal manera que la abstracción de la norma se concretice en la casuística y desde la idiosincrasia de cada país. Simón (2013) establece la necesidad de crear criterios orientadores en la aplicación del interés superior del niño, evitando de esa manera el abuso de discrecionalidad de la autoridad judicial.

Cuba tiene buenas prácticas en protocolos en sede judicial para la aplicación de los principios rectores del derecho de familia del interés superior de los NNA, aunque en la vía notarial tiene un gran vacío según lo expresa Abboud (2016), con la guía de buenas prácticas de los derechos personalísimos de los NNA en casos concretos, específicamente en aquellos que garantizan el desarrollo humano de estos como personas y la necesidad de coordinar con otras disciplinas en proteger el mejor interés de estos, en los procesos de cuido y crianza, así se garantizaría que la fundamentación teórica y práctica que realicen las autoridades se les aseguren la efectividad del derecho:

En Cuba se ha avanzado en la creación de la jurisdicción familiar por vía de las Instrucciones Nos. 187/2007 y 216/2012 del Consejo de Gobierno del Tribunal Supremo Popular, de las que han derivado protocolos, tales como: las metodologías paralacomparecencia, las reglasparalaconstitución yelfuncionamientodelequipo multidisciplinar en el proceso de familia y las reglas mínimas para la escucha de los menores de edad (p. 35). 
Por lo tanto, en Nicaragua se requiere profundizar en los estudios en materia de derechos de los NNA, para entenderlos y aplicarlos en los tres ámbitos: familia, sociedad y Estado. Además, se hace necesaria la existencia de protocolos de actuaciones, o bien, guías de buenas prácticas que garanticen la participación multidisciplinaria con el fin de dar una respuesta objetiva a los problemas que nos conduzcan a criterios evaluadores.

\section{Conclusiones}

La autoridad parental es una institución familiar que ha sufrido en el tiempo una transición a nuevas tendencias democratizantes, nacidas de la humanización de los Derechos Humanos especializados a favor de los hijos e hijas. La cual ha dado origen al cambio de paradigmas en que se han desarrollado las funciones y obligaciones familiares derivadas de la autoridad parental.

La doctrina irregular considera a la niñez y adolescencia como objeto de protección, en tanto la doctrina de protección integral de la niñez y adolescencia reconoce a la persona menor de edad como sujeto de derechos y obligaciones reconociéndole la dignidad, libertad e igualdad de trato en las relaciones parentales, asumidas con sus reservas por la sociedad. Algunas legislaciones más recientes como la de Argentina han incorporado tendencias democratizantes en la normativa, garantizando la participación activa de los NNA en diferentes ámbitos de su vida.

Los Códigos de Familia Centroamericanos han adecuado su normativa interna en lsque retoman los Derechos Humanos de los NNA reconocidos en la Convención sobre los Derechos del Niño, sin embargo, la nomenclatura oscila entre la antigua institución de patria potestad a la autoridad parental hasta la tendencia más moderna que le llaman responsabilidad parental, en el entendido que la autoridad no debe entenderse como autoritarismo de los progenitores en relación con los hijos e hijas. De igual manera no debe entenderse la postura democrática de relaciones parentales o responsabilidades parentales como eximente de responsabilidad en la función de guía, apoyo y conducción de los hijos e hijas mientras estos logran desarrollar singularmente sus competencias considerando la edad y el grado de madurez de cada uno.

La CDN establece como principios especiales y transversales en el derecho de familia, el del interés superior de la niñez y el de autonomía progresiva que reconoce a los NNA como sujetos de derechos, estos principios son indeterminados y requieren una interpretación dinámica y flexible de parte de la familia, sociedad y Estado. Nos insta a aprender a escuchar y abrir espacios de participación de las 
niñas, niños y adolescentes, así como al cambio de paradigma en el ejercicio de las relaciones parentales.

Los principios rectores del derecho de familia desde la humanización de los derechos de la niñez y adolescencia, relativos al interés superior del niño y a la autonomía progresiva, son de difícil interpretación y aplicación por la abstracción de su contenido y por la exigencia que implica la interpretación dinámica y flexible aplicada al caso concreto, por las autoridades judiciales, por eso es recomendable que si la autoridad judicial no tiene experiencia en realizar entrevista con el niño o niña, se haga acompañar de psicólogo (a), para que le ayude a abordar la entrevista y pueda descodificar la escucha del NNA de forma adecuada.

La igualdad de trato a los NNA en la familia, sociedad y Estado es aparente, en la práctica no se les da el mismo rango de valor a los derechos de estos en relación con los derechos de las personas adultas, ya que se demostró mediante análisis de sentencias que solamente en un $57.64 \%$ que equivale a 15 sentencias de los procesos de cuido y crianza fueron escuchados y de estos solamente 10 de ellas hacen una buena relación y consideración de la escucha de los NNA en el proceso, 3 de ellas hacen una relación sucinta de la escucha de estos y solo en 2 de ellas se hace referencia sin hacer ningún tipo de valoración.

De acuerdo con la complejidad de los casos y circunstancias que los rodean, así como von la edad de los NNA, el apoyo multidisciplinario es necesario para que lo resuelto por la autoridad judicial brinde mayor alcance en el ambiente familiar y se logre objetivamente alcanzar la tutela jurídica considerando parámetros o criterios multidisciplinares como, el de seguridad, confianza, afecto, estimulación de facultades del menor de edad, resguardando así el principio de protección adecuada.

Se recomienda unificar criterios de interpretación mediante la elaboración de protocolos de corte multidisciplinario; además, establecer la ruta de las actuaciones que conceptualicen los principios nacidos de la humanización de los derechos de los NNA, que consoliden formas de abordar la participación de estos en los diferentes procesos judiciales independientemente si son contenciosos o no, de igual manera que constituyan la forma de valorar la escucha de estos y de respetar su dignidad en un plano de igualdad objetiva sin discriminación alguna, respetando la libertad en la práctica diaria desde las tres aristas: familia, sociedad y Estado.

El cambio de paradigma radica en transformar la forma de educar, representar $\mathrm{y}$ atender a los hijos e hijas, por el accionar que ayude a crecer y a desarrollar competencias para la vida, acompañando, guiando y apoyándolos en su desarrollo personal, tal como lo exponen el artículo 5 de la CDN y el artículo 280 del CFN. 


\section{Referencias}

Abboud, N. (2016). El cuidado compartido. Especial referencia al derecho nicaragüense (Tesis inédita de doctorado). Universidad de La Habana, Cuba.

Abboud, N. (2016). Estudio introductorio al Código de Familia de Nicaragua (1ra. edición). Managua: Ed. Investigaciones y Publicaciones Jurídicas, Universidad Centroamericana.

Acuña, M. (2015). Aplicación judicial de la autonomía progresiva de los niños. El Mercurio. Recuperado: http://www.elmercurio.com/Legal/Noticias/Analisis-Juridico/2015/06/04/ Aplicacion-judicial-de-la-autonomia-progresiva-de-los-ninos.aspx

Acuña,M.(2015).Cambiosenlapatriapotestadyenespecialde su ejercicio conjunto. Revista de Derecho, No. 1, Vol. XXVIII, pp.55-57.

Asamblea General. (1989). Convención sobre los Derechos del Niño. Resolución 44/25, del 20 de noviembre de 1989.

Asamblea Nacional. (1998). Ley No. 287. Código de la Niñez y la Adolescencia. Publicado en La Gaceta Diario Oficial No. 97, del 27 de mayo de 1998. Nicaragua.

Asamblea Nacional. (2014). Constitución Política de la República de Nicaragua 1987, con susreformas incorporadas. Publicado enLa Gaceta Diario OficialNo. 32, del18 de febrero de 2014. Nicaragua.

Asamblea Nacional. (2014). Ley No. 870. Código de Familia. Publicado en La Gaceta Diario Oficial No. 190, del 8 de octubre del 2014. Nicaragua.

Benavides, D. (2006). Tendencias del derecho familiar en América Latina. Revista para el Análisis del Derecho. Recuperado http://www.indret.com/pdf/321_es.pdf

Cardona, J. (2013). El interés superior del niño, principio y fin del sistema de protección infantil. Miembro delComité de derechos del niño de la ONU. Conferencia. Recuperado de https://www.youtube.com/watch?v=6RllYOtouK8

Cillero,M.(s.f.).ElInterés SuperiordelNiñoenelMarco delaConvención sobrelos Derechos del Niño. Recuperado: http://www.iin.oea.org/IIN/cad/Participacion/pdf/el_interes_superior.pdf

Código Civil y Comercial de la Nación. (2014). Ministerio de Justicia y Derechos Humanos. Presidencia de la Nación. Argentina. Aprobado por ley 26.994. Promulgado según decreto 1795/2014. Infojus.

Código de Familia de Costa Rica. Ley No. 5476 del 21 de diciembre de 1973. Publicado en Alcance No. 20 en La Gaceta No. 24 del 5 de febrero de 1974. Recuperado de www.tse. go.cr/pdf/normativa/codigodefamilia.pdf 
Código de Familia de El Salvador. Asamblea Legislativa de El Salvador. Decreto No. 677. Publicado el 13 de diciembre de 1993. Diario Oficial No. 321. Última modificación con fecha 9 de febrero del 2017.

Código de Familia de Honduras Decreto No. 76-84. Publicado en Diario Oficial La Gaceta No. 24,394 del 16 de agosto de 1984.

Código de la Familia de la República dePanamá. Ley No.3, del17 de mayo de 1994.Publicada en la Gaceta Oficial No. 22.591 del 1 de agosto de 1994. Congreso Nacional.

Convención Americana sobre Derechos Humanos. (1969). Recuperado https://www.oas.org/ dil/esp/tratados_b-32_convencion_americana_sobre_derechos_humanos.htm

Corte Interamericana de Derechos Humanos. (1948). Cuadernillo de Jurisprudencia de la Corte Interamericana de Derechos Humanos, No. 5. Niños y Niñas.

Corte Interamericana de Derechos Humanos. Opinión Consultiva OC-17/2002, del 28 de agosto del 2002. Recuperado de www.corteidh.or.cr/docs/opiniones/seriea_17_esp.pdf

Famá, V. (2016). Jornada de responsabilidad parental. Universidad de Buenos Aires. Recuperado de https://www.youtube.com/watch?v=YXDbqX174HY

Fauné, A. (1995). Las familias, las mujeres, qué dice la realidad. Revista Envío, No. 160.

Gallego A. (2015). Participación Infantil. Historia de una relación de invisibilidad. Revista Latinoamericana de ciencias sociales, niñez y juventud. Volumen 13, No. 1. Recuperado de http://bilbioteca.claco.edu.ar

Gómez, O. (2010). La responsabilidad paterna y materna, principio y fin del derecho de familia. En Derecho de Familia Centroamericano: Costa Rica. San José, Costa Rica: Editorial Jurídica Continental.

Herrera, N. (2015). La participación del niño en el proceso a la luz de la CDN, las legislaciones de protección integral de derechos yelproyecto de código civil y comercial. Revista de Derecho de Familia y Personas, No. 3, año VII.

Herrera, M. (2016). El interés superior del niño. Conferencia. Recuperado de UBA. Recuperado de https://www.youtube.com/watch?v=ir8IV1hH1q0

Herrera, M. (2016). Los derechos de infancia y adolescencia en el Código Civily Comercial de la Nación: Claves para entender una nueva interacción legal. Universidad Nacional del Centro de la Provincia de Buenos Aires. Recuperado de http://www.cartapacio.edu.ar/ojs/index. php/ctp/article/view/1488 
Herrera, M. (s.f.). La democratización de las relaciones de familia; desafíos de la relación padres e hijos desde el principio de capacidad progresiva de niños, niñas y adolescentes. Revista Jurídica y Derechos del Niño. No. 11, p. 107, Unicef. Santiago.

Jaime, V.(2016). La Responsabilidad del Garante en el juicio de Alimentos y el Interés Superior de las niñas, niños y adolescentes. UNIANDES. Recuperado dspace.uniandes.edu.ec/ handle/123456789/4288

Kemelmajer, A. (2016). Derechos de la familia, adolescencia y niñez: una mirada crítica y contemporánea. Digital.

Kemelmajer, A. (2016). La Autonomía Progresiva. Recuperado https://www.youtube.com/ watch?v=iH5R9878Zmg

Kemelmajer, A. (2015). El principio de la autonomía progresiva en el código civil y comercial. Algunas reglas para su aplicación. Recuperado http://www.saij.gob.ar/aida-kemelmajer-carlucci-principio-autonomia-progresiva-codigo-civil-comercial-algunas-reglas-para-su-aplicacio n-dacf150461-2015-08-18/123456789-0abc-defg1640-51fcanirtcod

López, C. (2010). Anotaciones sobre Derecho de Familia y su Relación con el Derecho de la Niñez y la Adolescencia. En Derecho de Familia Centroamericano: Costa Rica. San José, Costa Rica: Editorial Jurídica Continental. Asamblea Nacional.

López, C. (2014). Adecuación de la Convención sobre los derechos del niño y la niña en las leyes, políticas públicas y restitución de derechos de la niñez y la adolescencia.

Loyarte, D. (2015). La familia y sus derechos. Divulgación popular de los Derechos de Familia, XVII CONGRESO Internacional de Derecho de Familia: La familia y los desafíos sociales. Argentina. Recuperada de: https://enfoquejuridico.org/2016/01/12/ laautoridad-parental-de-la-autoridad-a-la-responsabilidad-parental/

Marroquín, A. (2010). La custodia compartida. En Derecho de Familia Centroamericano: Costa Rica. San José, Costa Rica: Editorial Jurídica Continental.

Melendo, T. (2013). El ser humano: desarrollo y plenitud. Madrid: Ediciones Internacionales Universitarias-Upaep: Recuperado www.esposiblelaesperanza.com

Melendo, T.(2010). Persona, personalidad y libertad. En Metafísica y Persona. Filosofía, conocimiento y vida. Enero-julio, No. 3, versión impresa, Puebla, pp. 83-105; versión digital, Málaga. Recuperado http://metyper.com/persona-personalidad-y-libertad/

Meza, M. (2004). Derecho de Personas y Familia. Xerox Uca.

Naciones Unidas. Convención sobre los derechos del niño. Comité de los derechos del niño. Observaciones Generales. 
Nordenfelt, L. (2014). Modelos de dignidad en el cuidado: Contribuciones para el final de la vida. Cuadernos de Bioética, No. 66, vol. XXV. Universidad de Santiago deCompostela.

Ordeñana T. (2016). El Derecho de Familia en el nuevo Paradigma Constitucional. Quito: Cevallos Editora Jurídica.

Orozco, G. (2010). Apuntes sobre las relaciones madre, padre, hijos e hijas abordadas en el anteproyecto de Código de Familia de la República de Nicaragua. En Derecho de Familia Centroamericano: Costa Rica. San José, Costa Rica: Editorial Jurídica Continental.

Ortega I. (2002). El principio de Interés Superior del Niño en las situaciones de crisis familiar. Psicopatología Clínica, legal y forense. Vol. 2 (3).

Pérez, L. (2015). Temas de derecho notarial (con especial referencia al derecho nicaragüense). $1^{\text {a }}$. edición. Managua, Nicaragua: Editorial SENICSA.

Rocha,M.(2015).LaPersona delMenor, suinterés superior, su autonomía yellibre desarrollo de su personalidad. Actualidad Jurídica Iberoamericana, No. 2, 2015. pp. 43-86.

Quintero, A. (2005). La mujer y sus derechos desde la función familiar. Revista de ciencias sociales [en línea]. Recuperado de www.Redalyc.org

Simón, F.(2013). Interés superior del menor: Técnicas de reducción de la discrecionalidad abusiva (Tesis inédita de doctorado). Universidad de Salamanca, España.

Torrecuadrada, G. (2016). El interés superior del niño. Anuario Mexicano de De- recho Internacional, 1 (16), Recuperado de http://www.scielo.org.mx/scielo. php?script=sci_arttext\&pid=S1870-46542016000100131\&lng=es\&nrm=iso

Trejos, G., Ramírez, M. \& Benavides, D. (2010). Derecho de la Familia. San José: Editorial Jurícentro.

Velazco, M. (2008). La guarda y cuidado de los menores sujetos a la patria potestad. La Habana Cuba: Editorial ONBC.

Villabella, C. (2016). El Derecho Constitucional en Europa y en América Latina. México. Grupo Editorial Mariel S.C.

Vivas, I. (2010). Las transformaciones del derecho de familia desde una perspectiva de género. Departamento de Derecho Civil e Internacional Privado. España: Universidad de Sevilla.

Recibido: $15 / 10 / 2017$

Aceptado: 14/3/2017 